\title{
Chromosomal damage and apoptosis analysis in exfoliated oral epithelial cells from mouthwash and alcohol users
}

\author{
Rodrigo dos Santos Rocha, José Roberto Cardoso Meireles and Eneida de Moraes Marcílio Cerqueira \\ Laboratório de Genética Toxicológica, Departmento de Ciências Biológicas, \\ Universidade Estadual de Feira de Santana, Feira de Santana, BA, Brazil.
}

\begin{abstract}
Chromosomal damage and apoptosis were analyzed in users of mouthwash and/or alcoholic beverages, using the micronucleus test on exfoliated oral mucosa cells. Samples from four groups of 20 individuals each were analyzed: three exposed groups (EG1, EG2 and EG3) and a control group (CG). EG1 comprised mouthwash users; EG2 comprised drinkers, and EG3 users of both mouthwashes and alcoholic beverages. Cell material was collected by gently scraping the insides of the cheeks. Then the cells were fixed in a methanol/acetic acid (3:1) solution and stained and counterstained, respectively, with Schiff reactive and fast green. Endpoints were computed on 2,000 cells in a blind test. Statistical analysis showed that chromosomal damage and apoptosis were significantly higher in individuals of groups EG1 and EG3 than in controls ( $p<0.005$ and $p<0.001$, respectively). No significant difference in chromosomal damage and apoptosis was observed between the exposed groups. In EG2, only the occurrence of apoptosis was significantly higher than in the controls. These results suggest that mouthwashes alone or in association with alcoholic drinks induce genotoxic effects, manifested as chromosomal damage and apoptosis. They also suggest that alcoholic drinks are effective for stimulating the process of apoptosis. However, these data need to be confirmed in larger samples.
\end{abstract}

Keywords: micronucleus, apoptosis, mouthwash, alcoholic beverages.

Received: March 29, 2014; Accepted: June 18, 2014.

\section{Introduction}

Oral cancer is one of the cancer types with the highest incidence worldwide, ranking alongside cancer of the pharynx as the sixth main cause of malignancy (Saman, 2012). Several risk factors associated with the development of oral cancer have been identified, and cigarette smoking has been the most consistently reported, particularly when combined with alcohol consumption (Wünsch-Filho, 2002; Rodriguez et al., 2004; Varela-Lema et al., 2010). The association between drinking and oral cancer per se has, however, been a source of controversy in the literature, with some reports stating that alcohol alone does not induce the development of this neoplasia (Jaber et al., 1998), whereas in several other studies this association was observed (Altieri et al., 2004; Benedetti et al., 2009; Cancela et al., 2009; Goldstein et al., 2010).

Mouthwashes are frequently used in oral hygiene. However, their effectiveness has been questioned, and it has even been suggested that they may contribute to pro-

Send correspondence to Eneida de Moraes Marcílio Cerqueira. Laboratório de Genética Toxicológica, Departmento de Ciências Biológicas, Universidade Estadual de Feira de Santana, Av. Transnordestina s/n, 44036-900 Feira de Santana, BA, Brazil. E-mail: eneida.cerqueira@gmail.com. moting oral cancer, since many of these products contain alcohol in their composition. This alcohol serves as a solvent for other components or as a preservative of the product (Marinho and Araujo, 2007).

Oral cancer, like other types of cancer, results from mutations in genes that are involved in DNA repair mechanisms and in the control of cell proliferation and cell differentiation. In addition, changes in genes that control apoptosis pathways may contribute to promote cancer, since cells with damaged DNA which escape from death can produce genetically modified offspring (Hanahan and Weinberg, 2000). The risk factors for cancer development are therefore thought to act by inducing changes in genetic material and thereby leading to the occurrence of both gene mutations and chromosomal aberrations.

The identification of genetic alterations is an important measure for cancer prevention, since these changes occur before any clinical symptom of the disease is manifested. The effectiveness of micronucleus tests performed in exfoliated oral epithelium cells for detecting genotoxic effects following exposure to mutagens has been recognized in many studies (Machado-Santelli et al., 1994; Salama et al., 1999; Cavallo et al., 2005; Sailaja et al., 2006). Micronuclei are formed by chromosome fragments or whole chromosomes that fail to be included in the nuclei 
during cell division. They remain in the cytoplasm of interphase cells, where they can be observed as structures resembling nuclei (Holland et al., 2008). It has been noted that the micronucleus test is a valuable tool for oral carcinogenesis risk assessment, since the presence of micronuclei at high frequencies indicates a greater likelihood of developing cancer (Saran et al., 2008). The sensitivity of the test is improved if performed in accordance with the protocols published by Tolbert et al. (1992) and Thomas et al. (2009). According to these authors, in addition to evaluating micronuclei, the degenerative nuclear alterations characteristic to epithelium undergoing renovation, but which - when seen in excess - are indicative of apoptosis (karyorrhexis, condensed chromatin and pyknosis), should also be evaluated. Degenerative nuclear alterations indicate that additional genotoxic effects due to exposure are occurring.

In the present study, the genotoxic effects consequent to mouthwash use and alcohol consumption were analyzed, using the micronucleus test according to the protocols of Tolbert et al. (1992) and Thomas et al. (2009).

\section{Materials and Methods}

\section{Subjects}

The sample comprised 80 healthy individuals (both males and females) who were seen routinely in dental clinics at the Feira de Santana State University, Bahia, Brazil. These individuals were all students at this University, with ages ranging from 20 to 30 years. They were distributed into four groups of 20 individuals each (three exposed groups and one control group):

Exposed group 1 (EG1): mouthwash users;

Exposed group 2 (EG2): alcohol consumers;

Exposed group 3 (EG3): mouthwash and alcohol users;

Control group (CG): individuals not exposed to any known mutagens or carcinogens.

A questionnaire on demographic data, lifestyle factors (smoking habit, drinking and mouthwash use) and exposure to genotoxic chemicals and X-rays was applied.

Smokers and individuals who said that they had been exposed to genotoxic agents were excluded from the study, as well as those presenting lesions of the oral mucosa visible at clinical examination.

\section{Sample collection and cytological preparations}

In the exposed groups, the time elapsed between the last use of alcohol and/or mouthwash and the collection of the sample was at least one week. The material was collected by gently scraping the insides of the cheeks, using a cervical brush. Buccal smears were prepared on clean slides, with addition of two drops of saline solution $(0.9 \%$ $\mathrm{NaCl}$ ). Then the slides were air-dried and fixed in a $3: 1$ methanol/acetic acid solution for ten minutes. Staining and counterstaining were done 24 hours later, using, respectively, Schiff reactive and fast green (1\%).

\section{Cytological analysis}

The slides were analyzed under an optical microscope in a blind test. For each individual, 2,000 cells were evaluated. Micronuclei and degenerative nuclear alterations indicative of apoptosis (sum of karyorrhexis, pyknosis and condensed chromatin) were identified in accordance with the criteria of Tolbert et al. (1992) and Thomas et al. (2009) (Figure 1).

\section{Statistical analysis}

Age-related differences between the groups were analyzed using one-way ANOVA, assuming that the data had a normal distribution. Gender distribution in the groups was evaluated by means of the chi-square test. Two indexes were established to evaluate differences between groups regarding mouthwash use (MI) and alcohol consumption (AI). Values were attributed to assess the MI of groups EG1 and EG3, considering use frequency (daily or weekly), duration (in years) and formulation (alcoholic or nonalcoholic). After multiplication of the values obtained, the median was calculated, and the chi-square test was used to evaluate the differences between these groups. Values were attributed to assess the AI, considering initially the kind of beverage multiplied by the number of drinks $(200 \mathrm{~mL})$ consumed. Then the sum of the obtained values was multiplied by the values attributed to frequency and duration of this habit. The differences between groups EG1 and EG3 were calculated similarly. Cytological endpoints were analyzed using the conditional test for comparing proportions in situations in which events are rare (Bragança-Pereira, 1991). This test is an alternative to the chi-square test and is similar to Fisher's exact test (Kalbfleisch, 1979). It is considered to be appropriate for evaluating cytogenetic events when a great number of cells are required to detect endpoints that occur at low frequencies.

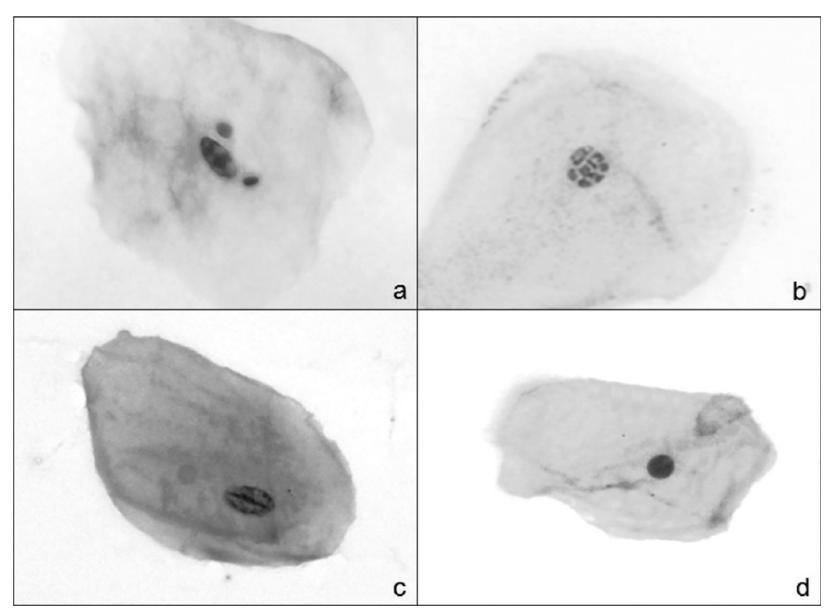

Figure 1 - Cells presenting two micronuclei (a), karyorrhexis (b), condensed chromatin (c), and pyknosis (d). 


\section{Ethical issues}

This study was approved by the Ethics Committee of the Universidade Estadual de Feira de Santana (Protocol 007/2009). Informed consent statements were signed by all participants and confidentiality was ensured.

\section{Results}

The mean age and standard deviation obtained for the control group and exposed groups 1, 2 and 3 were, respectively: $\bar{X}=24.75 \pm 2.54 ; \bar{X}=25.15 \pm 2.59 ; \bar{X}=24.45 \pm$ 2.37; and $\bar{X}=24.35 \pm 1.98$. One-way ANOVA did not show any significant difference $\left(\mathrm{F}_{3.76}=0.4307\right.$, $\mathrm{p}=0.7316)$. There were also no differences between the groups regarding gender, as determined using the chisquare test: $\chi^{2}=4.396 ; \mathrm{DF}=3 ; \mathrm{p}=0.2218$. Seven subjects in EG2 and 11 subjects in EG3 reported a drinking time of less than five years, while 13 subjects in EG2 and nine in EG3 informed that they had been drinking for more than five years. The use of mouthwash for less than one year was reported by six subjects in EG1 and by five subjects in EG3. Fourteen subjects of EG1 and 15 of EG3 reported mouthwash use for more than one year. The data regarding gender distribution, drinking and mouthwash use are presented in Table 1.

The numbers of micronuclei observed in the individuals of the control group and exposed groups 1, 2 and 3 were, respectively, 2, 12, 8, and 13. Statistical analysis showed differences between the groups $\left(\chi^{2}=8.5428\right.$; DF $=3$; $\mathrm{p}<0.05)$. Chi-square partitions showed that the occurrence of micronuclei was significantly higher in the individuals of EG1 and EG3 than in the individuals of the control group. However, there were no differences in micronucleus occurrence among the exposed groups or between EG2 and the control group (Table 2).

The data regarding degenerative nuclear alterations indicative of apoptosis are presented in Table 3.

Table 4 shows that the occurrence of apoptosis, evaluated through the sum of karyorrhexis, condensed chromatin and pyknosis, was significantly higher in the individuals of EG1, EG2 and EG3 than in the individuals of the control group. No differences were observed among the exposed groups.

\section{Discussion}

Oral cancer is one of the cancer types with highest incidence worldwide, especially in underdeveloped or developing countries (Guerra et al., 2005). The high cost of treating this disease, mainly when detected at advanced stages, makes this a major public health problem and has stimulated a constant search for preventive measures.

The importance of chromosome abnormalities as biomarkers has been highlighted in many studies which have shown that a greater frequency of such abnormalities is pre-
Table 1 - Sample characteristics relative to gender, drinking and mouthwash use.

\begin{tabular}{|c|c|c|c|c|}
\hline \multirow[t]{3}{*}{ Characteristic } & \multicolumn{4}{|c|}{ Group (n) } \\
\hline & \multicolumn{2}{|c|}{ Exposed } & \multicolumn{2}{|c|}{ Control } \\
\hline & EG 1 & EG 2 & EG 3 & CG \\
\hline \multicolumn{5}{|l|}{ Gender } \\
\hline Female & 8 & 6 & 4 & 10 \\
\hline Male & 12 & 14 & 16 & 10 \\
\hline \multicolumn{5}{|c|}{ Drinking frequency (per week) } \\
\hline Once & - & 7 & 13 & - \\
\hline $2-3$ times & - & 13 & 7 & - \\
\hline \multicolumn{5}{|l|}{ Type of drink } \\
\hline Distilled & - & 2 & 0 & - \\
\hline Fermented & - & 11 & 15 & - \\
\hline Distilled and fermented & - & 7 & 5 & - \\
\hline \multicolumn{5}{|c|}{ Time of drinking habit (years) } \\
\hline$<5$ & - & 7 & 11 & - \\
\hline$>5$ & - & 13 & 9 & - \\
\hline \multicolumn{5}{|l|}{ Mouthwash use frequency } \\
\hline Daily & 9 & - & 6 & - \\
\hline 2-4 times per week & 11 & - & 14 & - \\
\hline \multicolumn{5}{|l|}{ Type of mouthwash } \\
\hline Alcoholic & 11 & - & 16 & - \\
\hline Non-alcoholic & 9 & - & 4 & - \\
\hline \multicolumn{5}{|c|}{ Time of mouthwash use (years) } \\
\hline$<1$ & 6 & - & 5 & - \\
\hline$>1$ & 14 & - & 15 & - \\
\hline
\end{tabular}

dictive of higher cancer risk (Bloching et al., 2000; Casartelli et al., 2000; Kamboj and Mahajan, 2007; Chatterjee et al., 2009).

In the present study, the micronucleus test was performed on exfoliated oral mucosa cells, in accordance with the protocols developed by Tolbert et al. (1992) and Thomas et al. (2009). These protocols were pointed out as a valuable tool for assessing genotoxic damage in populations exposed to a variety of mutagens (Freita et al., 2005; Cerqueira et al., 2008). The efficiency of this test is notably greater when the exposure to the mutagenic agent occurs directly on the oral epithelium. Examples of such exposure include smoking and the variables analyzed in the present study, i.e., the drinking habit and mouthwash use.

The genotoxic effects of alcohol consumption, reflected by a greater occurrence of micronuclei, have been a source of controversy in the literature. In a study that assessed the effects of drinking and smoking on the induction of micronuclei in oral mucosa cells, Bloching et al. (2000) reported that higher frequencies of these structures only occurred as a result of tobacco consumption. 
Table 2 - Micronucleus (MN) occurrence in exposed (EG1, EG2 and EG3) and control (CG) groups

\begin{tabular}{|c|c|c|c|c|c|c|}
\hline Groups & MN (obs.) & MN (exp.) & Total cells & MN (\%) Mean \pm SE & Chi-square $(\mathrm{DF}=3)$ & Chi-square partitions $(\mathrm{DF}=1)$ \\
\hline EG1 & 12 & 8.75 & 40,000 & $0.30 \pm 0.08$ & \multirow{6}{*}{$\chi^{2}=8.5428 p<0.05$} & EG1 vs. CG: $\chi^{2}=7.1428 p<0.01$ \\
\hline EG2 & 8 & 8.75 & 40,000 & $0.20 \pm 0.06$ & & EG2 vs. CG: $\chi^{2}=3.600 ; p>0.05$ \\
\hline EG3 & 13 & 8.75 & 40,000 & $0.33 \pm 0.07$ & & EG3 vs. CG: $\chi^{2}=8.0667 ; p<0.05$ \\
\hline CG & 2 & 8.75 & 40,000 & $0.05 \pm 0.03$ & & EG1 vs. EG2: $\chi^{2}=0.800 ; p>0.30$ \\
\hline \multirow[t]{2}{*}{ Total } & 35 & 35 & 160,000 & & & EG1 vs. EG3: $\chi^{2}=0.0400 ; \mathrm{p}>0.80$ \\
\hline & & & & & & EG2 vs. EG3: $\chi^{2}=1.1905 ; \mathrm{p}>0.20$ \\
\hline
\end{tabular}

obs: observed; exp: expected.

Table 3 - Degenerative nuclear alterations indicative of apoptosis observed in the exposed (EG1, EG2 and EG3) and the control (CG) groups.

\begin{tabular}{lccccc}
\hline Group & N & $\begin{array}{c}\text { Total } \\
\text { cells }\end{array}$ & Karyorrhexis & $\begin{array}{c}\text { Condensed } \\
\text { chromatin }\end{array}$ & Pyknosis \\
\hline EG1 & 20 & 40,000 & 321 & 97 & 28 \\
EG2 & 20 & 40,000 & 291 & 140 & 17 \\
EG3 & 20 & 40,000 & 258 & 120 & 19 \\
CG & 20 & 40,000 & 156 & 94 & 16 \\
\hline
\end{tabular}

Higher occurrences of micronuclei in exfoliated cells from the tongues of alcohol-dependent individuals were reported by Reis et al. (2002) in a case-control study. The numbers of micronuclei were also higher in exfoliated mucosal cells from the inside of the cheeks of the individuals of the exposed group, but the difference was not statistically significant.

Stich and Rosin (1983) also evaluated the occurrence of micronuclei among consumers of alcohol and/or tobacco. They reported a greater occurrence of these structures only in individuals with both habits. Additive effects of these habits with regard to inducing micronuclei in exfoliated oral epithelium cells were also described by Kassie et al. (2001). Bohrer et al. (2005) analyzed exfoliated cells from three sites in the mouth (tongue, upper lip and buccal floor) and found, at all three sites, a greater number of micronuclei in alcohol consumers and manufactured cigarette users than in a control group and in a group that only consumed tobacco. However, the difference between the groups was not statistically significant.

After allowing for the differences in the anatomical sites investigated by Reis et al. (2002) and Bohrer et al. (2005), the results of the present study are in agreement with theirs. Thus, the number of micronuclei observed in alcohol consumers (EG2) was greater than in the controls (CG). The comparison between these results showed a marginal statistical significance, which strongly suggests the need of further studies in larger samples, before reliable conclusions regarding the mutagenic potential of alcoholic drinks can be drawn.

It should also be pointed out that evaluations of results from different studies must take into account the differences in variables regarding alcohol consumption, such as the kind of drink, the quantity consumed and the duration of the habit.

There are few reports in the literature regarding the evaluation of the genotoxicity of mouthwashes for humans. Eren et al. (2002) investigated the occurrence of DNA damage using the Comet test and detected a greater occurrence of such damage in peripheral lymphocytes and exfoliated oral epithelium cells of 13 individuals who had used mouthwashes containing chlorhexidine for 18 days.

Freita et al. (2005) observed a greater occurrence of micronuclei in mouthwash users, noting however that their results should be considered with caution, given the very small number of users (only five subjects of which, moreover, three consumed both tobacco and alcohol). A greater

Table 4 - Apoptosis occurrence in the exposed (EG1, EG2 and EG3) and control (CG) groups.

\begin{tabular}{lcccccc}
\hline Group & Apop obs. & Apop. exp. & Total cells & Apoptosis (\%) mean \pm SE & Chi-square (DF = 3) & Chi-square partitions (DF=1) \\
\hline EG1 & 446 & 389.25 & 40,000 & $11.15 \pm 2.22$ & EG1 vs. CG: $\chi^{2}=45.505 ; \mathrm{p}<0.001$ \\
EG2 & 448 & 389.25 & 40,000 & $11.20 \pm 2.02$ & EG2 vs. CG: $\chi^{2}=46.392 ; \mathrm{p}<0.001$ \\
EG3 & 397 & 389.25 & 40,000 & $9.93 \pm 1.37$ & $\chi^{2}=56.321 \mathrm{p} 0.001$ & EG3 vs. CG: $\chi^{2}=25.884 ; \mathrm{p}<0.001$ \\
CG & 266 & 389.25 & 40,000 & $6.65 \pm 0.85$ & EG1 vs. EG2: $\chi^{2}=0.004 ; \mathrm{p}>0.90$ \\
Total & 1,557 & 1,557 & 160,000 & & EG1 vs. EG3: $\chi^{2}=2.848 ; p>0.10$ \\
& & & & & EG2 vs. EG3: $\chi^{2}=3.078 ; p>0.05$ \\
\hline
\end{tabular}

Apop obs: Apoptosis observed; Apop exp: Apoptosis expected. 
frequency of micronuclei associated with the use of mouthwashes containing chlorhexidine digluconate, alcohol and glycerol was further observed by Carlin et al. (2012).

It has been suggested that the alcohol present in mouthwashes is the component responsible for the association between this habit and the occurrence of oral cancer (McCullough and Farah, 2008) and for the genotoxic effects described (Casartelli et al., 2000; Eren et al., 2002; Carlin et al., 2012). In the present study, although the frequency of micronuclei observed was highest in the cells obtained from the individuals in exposed group 3 (EG3), who were users of both mouthwashes and alcoholic drinks, the comparison with group 1 (EG1), formed by individuals who only used mouthwashes, did not show any statistically significant difference. Thus, no additive and/or synergistic effects can be inferred.

Some mouthwashes are formulated with higher alcohol content than that of some alcoholic drinks (Pinêra et al., 1996). In addition, as these antiseptics are swilled around in the mouth, they stay in contact with the oral epithelium for a longer time than when an alcoholic beverage is ingested. This could be the reason why no greater occurrence of micronuclei was detected in the subjects who only used alcoholic drinks (EG2) compared to the controls (CG), whereas a difference was found with regard to the mouthwash users (EG1).

Despite the marginal significance obtained by comparing the occurrence of micronuclei in the drinkers and the control group, genotoxic effects of this habit were shown by analyzing the occurrence of degenerative nuclear alterations, which were significantly more frequent in the drinkers. This indicates that an apoptotic response to the DNA damage was induced, which may even have masked the actual occurrence of micronuclei. These results are in agreement with those reported by Freita et al. (2005), who also observed genotoxic effects of the drinking habit, represented only by a greater occurrence of apoptosis.

A more frequent occurrence of apoptosis was also observed when either of the other two exposed groups (EG2 and EG3) was compared with the control group. This suggests that mouthwashes are genotoxic, as already shown by the induction of micronuclei by mouthwash use, whether alone or in association with alcohol consumption.

Gender and age should always be taken into consideration in studies assessing the occurrence of micronuclei in humans. Since the groups studied here did not differ regarding these variables, such associations were not investigated.

Despite the controversial results obtained in studies on the occurrence of micronuclei associated with drinking habits, the accumulated evidence indicating the risks of such exposure is sufficient to discourage taking up these habits and to encourage quitting. Despite also the small number of studies indicating the genotoxicity of mouthwashes, there is evidence to advise against their indiscrimi- nate use. These data need, however, to be confirmed in larger samples.

\section{Acknowledgments}

This study was supported by the National Research Council (CNPq) and Feira de Santana State University (UEFS).

\section{References}

Altieri A, Bosetti C, Gallus S, Franceschi S, Dal Maso L, Talamini R, Levi F, Negri E, Rodriguez T and La Vecchia C (2004) Wine, beer and spirits and risk of oral and pharyngeal cancer: A case-control study from Italy and Switzerland. Oral Oncol 40:904-909.

Benedetti A, Parent ME and Siemiatycki J (2009) Lifetime consumption of alcoholic beverages and risk of 13 types of cancer in men: Results from a case-control study in Montreal. Canc Epidemiol 32:352-362.

Bloching M, Hofmann A, Lautenschläger C, Berghaus A and Grummt T (2000) Exfoliative cytology of normal buccal mucosa to predict the relative risk of cancer in the upper aerodigestive tract using the MN-assay. Oral Oncol 36:550555.

Bohrer PL, Filho MS, Paiva RL, da Silva IL and Rados PV (2005) Assessment of micronucleus frequency in normal oral mucosa of patients exposed to carcinogens. Acta Cytol 49:265272.

Bragança-Pereira CA (1991) Teste estatístico para comparar proporções em problemas de citogenética. In: Rabello-Gay MN, Rodrigues MA, La R and Monteleone-Neto R (eds) Mutagênese, Carcinogênese e Teratogênese: Métodos e Critérios de Avaliação. Sociedade Brasileira de Genética, São Paulo, pp 113-121.

Cancela MC, Ramadas K, Fayette JM, Thomas G, Muwonge R, Chapuis F, Thara S, Sankaranarayanan R and Sauvaget C (2009) Alcohol intake and oral cavity cancer risk among men in a prospective study in Kerala, India. Community Dent Oral Epidemiol 37:342-349.

Carlin V, Matsumoto MA, Saraiva PP, Artioli A, Oshima CT and Ribeiro DA (2012) Cytogenetic damage induced by mouthrinses formulations in vivo and in vitro. Clin Oral Invest 16:813-820.

Casartelli G, Bonatti S, De Ferrari M, Scala M, Mereu P, Margarino G and Abbondandolo A (2000) Micronucleus frequencies in exfoliated buccal cells in normal mucosa, precancerous lesions and squamous cell carcinoma. Anal Quant Cytol Histol 22:486-492.

Cavallo D, Ursini CL, Perniconi B, Francesco AD, Giglio M, Rubino FM, Marinaccio A and Iavicoli S (2005) Evaluation of genotoxic effects induced by exposure to antineoplastic drugs in lymphocytes and exfoliated cells of oncology nurses and pharmacy employees. Mutat Res 587:45-51.

Cerqueira EM, Meireles JR, Lopes MA, Junqueira VC, GomesFilho IS, Trindade S and Machado-Santelli GM (2008) Genotoxic effects of X-rays on keratinized mucosa cells during panoramic dental radiography. Dentomaxillofacial Radiol 37:398-403.

Chatterjee S, Dhar S, Sengupta B, Ghosh A, De M, Roy S, Raychowdhury R and Chakrabarti S (2009) Cytogenetic 
monitoring in human oral cancers and other oral pathology: The micronucleus test in exfoliated buccal cells. Toxicol Mech Meth 19:427-433.

Eren K, Özmeriç N and Sardas S (2002) Monitoring of buccal epithelial cells by alkaline comet assay (single cell gel electrophoresis technique) in cytogenetic evaluation of chlorhexidine. Clin Oral Invest 6:150-154.

Freita VS, Lopes MA, Meireles JRC, Reis L and Cerqueira EMM (2005) Efeitos genotóxicos de fatores considerados de risco para o câncer bucal. Rev Baiana Saúde Pública 29:189-199.

Goldstein BY, Chang SC, Hashibe M, La Vecchia C and Zhang ZF (2010) Alcohol consumption and cancers of the oral cavity and pharynx from 1988 to 2009: An update. Eur J Cancer Prev 19:431-465.

Guerra MR, Gallo CVM and Mendonça GAS (2005) Risco de câncer no Brasil: Tendências e estudos epidemiológicos mais recentes. Rev Bras Cancerol 51:227-234.

Hanahan D and Weinberg RA (2000) The hallmarks of cancer. Cell 100:57-70.

Holland N, Bolognesi C, Kirsch-Volders M, Bonassi S, Zeiger E, Knasmueller S and Fenech M (2008) The micronucleus assay in human buccal cells as a tool for biomonitoring DNA damage: The HUMN project perspective on current status and knowledge gaps. Mutat Res 659:93-108.

Jaber MA, Porter SR, Scully C, Gilthorpe MS and Bedi R (1998) The role of alcohol in non-smokers and tobacco in nondrinkers in the aetiology of oral epithelial dysplasia. Int $\mathbf{J}$ Cancer 77:333-336.

Kalbfleisch JG (1979) Probability and Statistical Inference. Springer-Verlag, New York, 342 pp.

Kamboj M and Mahajan S (2007) Micronucleus: An upcoming marker of genotoxic damage. Clin Oral Invest 11:121126.

Kassie F, Darroudi F, Kundi M, Schulte-Hermann R and Knasmüller S (2001) Khat (Catha edulis) consumption causes genotoxic effects in humans. Int J Cancer 92:329-332.

Machado-Santelli GM, Cerqueira EMM, Oliveira CT and Bragança Pereira CA (1994) Biomonitoring of nurses handling antineoplastic drugs. Mutat Res 322:203-208.

Marinho BVS and Araujo ACS (2007) O uso de enxaguatórios bucais sobre a gengivite e o biofilme dental. Int J Dent Recife 6:124-131.

McCullough MJ and Farah CS (2008) The role of alcohol in oral carcinogenesis with particular reference to alcoholcontaining mouthwashes. Aust Dent J 53:302-305.
Pinêra K, Nogueira ACA and Consolaro A (1996) Determinação do teor alcoólico de anti-sépticos bucais e carcinogênese bucal química. Rev Bras Ciênc Estomatol 1:13-17.

Reis SRA, Sadigursky M, Andrade MGSA, Soares LPS, Santo ARE and Bôas DSV (2002) Efeito genotóxico do etanol em células da mucosa bucal. Pesq Odontol Bras 16:221-225.

Rodriguez T, Altieri A, Chatenoud L, Gallus S, Bosetti C, Negri E, Franceschi S, Levi F, Talamini R and La Vecchia C (2004) Risk factors for oral and pharyngeal cancer in young adults. Oral Oncol 40:207-213.

Sailaja N, Chandrasekhar M, Rekhadevi PV, Mahboob M, Rahman MF, Vuyyuri SB, Danadevi K, Hussain SA and Grover P (2006) Genotoxic evaluation of workers employed in pesticide production. Mutat Res 609:74-80.

Salama SA, Serrana M and Au WW (1999) Biomonitoring using accessible human cells for exposure and health risk assessment. Mutat Res 436:99-112.

Saman D (2012) A review of the epidemiology of oral and pharyngeal carcinoma: Update. Head Neck Oncol 4:e1.

Saran R, Tiwari RK, Reddy PP and Ahuja YR (2008) Risk assessment of oral cancer in patients with pre-cancerous states of the oral cavity using micronucleus test and challenge assay. Oral Oncol 44:354-360.

Stich HF and Rosin MP (1983) Quantitating the synergistic effect of smoking and alcohol consumption with the micronucleus test on human bucal mucosa cells. Int J Cance 31:305-308.

Thomas P, Holland N, Bolognesi C, Kirsch-Volders M, Bonassi S, Zeiger E, Knasmueller S and Fenech M (2009) Buccal micronucleus cytome assay. Nat Prot 4:825-837.

Tolbert PE, Shy CM and Allen JW (1992) Micronuclei and other nuclear anomalies in buccal smears: Methods development. Mutat Res 271:69-77.

Varela-Lema L, Ruano-Ravina A, Crespo MAJ and Barros-Dios JM (2010) Tobacco consumption and oral and pharyngeal cancer in a Spanish male population. Canc Lett 288:28-35.

Wünsch-Filho V (2002) The epidemiology of oral and pharynx cancer in Brazil. Oral Oncol 38:737-746.

Associate Editor: Carlos R. Machado

License information: This is an open-access article distributed under the terms of the Creative Commons Attribution License, which permits unrestricted use, distribution, and reproduction in any medium, provided the original work is properly cited. 